\title{
Editorial: Research universities in East Asia—graduate student and faculty perspectives
}

\author{
K. C. Ho ${ }^{1} \cdot$ Gerard A. Postiglione ${ }^{2} \cdot$ Futao Huang $^{3}$
}

Published online: 22 June 2018

(c) Education Research Institute, Seoul National University, Seoul, Korea 2018

East Asia (including South East Asia and North East Asia) has seen systematic changes in higher education as its major universities adapt to international trends and remain relevant to national priorities. By staying globally engaged with significant government funding, East Asia's major universities have rose rapidly in the international rankings (Huang 2015a, b; Marginson 2007; Mohrman et al. 2008; Postiglione 2015). They have restructured their capacity to provide teaching and research, diversified their curriculum, promoted multiculturalism on campus, increased the number of international students, and intensified and upgraded their doctoral student programmes (Ho 2014). Leading East Asian economies like Japan, Singapore, South Korea, Taiwan, Hong Kong, and the Chinese mainland are experiencing a demographic shift which rebalances the sources of student enrolment. In this context, talent migration has become more pronounced with expanding linkages of international students who graduated from their host universities (Rosenzweig 2008). Universities recruit an increasing number of overseas faculty from a wider net of countries. They have also increased their English language based training, as a way of increasing research output (Byun et al. 2013).

While doctoral education has been embedded within these changes, its significance has been supported by a national economic narrative of research and development. As East Asia's economic development moved beyond its low wage, labor intensive phase, the state narratives of economic restructuring placed expectations on universities to drive innovation by increased attention on the training

\section{K. C. Ho}

sochokc@nus.edu.sg

1 Department of Sociology, National University of Singapore, Singapore, Singapore

2 Faculty of Education, University of Hong Kong, Pokfulam, Hong Kong SAR, China

3 Research Institute for Higher Education, Hiroshima University, Hiroshima, Japan of researchers (Wong 2013; Soofi 2016). This training is imagined to result in the staffing of three important sectors. First, doctoral training is important for the support of key industries which are the backbone of the country's economic development and international economic competitiveness as the labor intensive industries move into countries with lower labor costs. Second, the training of young scientists becomes a key for start-up ventures which deploy research breakthroughs for new product development. Third, universities continue to look at home and abroad more actively for the staffing of its new generation of academics to improve on its reputational ranking (Postiglione 2013).

Collectively, these trends point to the growing importance of understanding the role and impact of doctorial training in Asia. If doctoral training is going to have its anticipated impact in the advanced economies of East Asia, it is important to build an understanding of the leading universities' preparatory process to train and prepare future researchers and scholars. This includes the students' own socialization experiences and their internalization of professional norms and practices. Such an understanding should examine the nature of the doctoral programme in terms of the coursework, the social milieu, and university facilities (Gibbs et al. 2015; Faupel-Badger et al. 2015). This requires an analysis of the transformative experience of being through the doctoral program and its effects in the shaping of student outlooks. A key element in the doctoral program is the nature of the supervisory process and the contrast in the supervisory mentoring process and peer learning.

Nevertheless, academic research on doctoral training is a relatively new arena and doctoral training has been considered a black-box in the field of higher education studies in East Asia because much of policy effort has been focussed on undergraduate education. Because of relative weakness in graduate education as well as higher preference towards foreign degree holders, universities in this region relied for too long on doctoral training on the Western universities. However, after the initial phase of economic take-off ended, 
and as the era of international ranking of universities began, the Asian economies began to see the need for supporting research intensive universities and doctoral education and training.

This special issue looks into the black-box of doctoral training through collaborative initiatives by selected leading research universities in East Asia: The University of Hong Kong, National University of Singapore, Peking University, Seoul National University, and Tsinghua University. The research team has been working for 3 years (2015-2017) to understand and analyze doctoral training. The seven papers included in this special issue address key aspects of doctoral education programmes which researchers, policy makers and incoming graduate students would do well to consider. The special issue features seven papers based on author-collected survey data that examine student aspirations, programme evaluation and satisfaction, and anticipation of labor market entry and career plan.

As top research universities become increasingly competitive in attracting and recruiting the best graduate students in respective disciplines and programmes, they will need to be more strategic about the reasons for student satisfaction regarding what their programmes can offer.

The overview paper by Shin and colleagues highlights the changing higher education landscape in East Asia and the role of national governments, academics, and students in the shaping of the research intensive university in Asia. We thank to Professor Eunyoung Kim for data collection and analysis of the US case research university reported in this overview article.

The study by Shin and colleagues found that socio-cultural factors, motivation, and job market perspectives are all critical for levels of graduate students' satisfaction with their program. However, socio-cultural factors are discussed from cultural contexts in Korea where closed academic network is a serious issue in academia as well as in the larger society.

Jung looked at the process through which students learn professional skills, values, and norms in their doctoral program. Her analysis shows how supervisory style influences doctoral students' professional competencies. Interestingly, the type of professional can have a positive impact on attitudes rather than only on task- or idea-oriented skills.

Shi and her colleagues argue that the transformation of doctoral education features two simultaneous processes: academic professionalization and scholarly socialization. Institutional environment, academic advisors, and more importantly the interaction between these factors and individual students play the key roles in the transformation.

As indicated in the literature review, the training of doctoral students has been underpinned by a strong state narrative. Academics and university officials alike point to the importance of recruiting high quality graduate students. However, whether doctoral students live up to the expectations of governments and universities which recruit them depends heavily on how they see their career plans.

The choice of career pathways depends on broad disciplinary opportunities. Using two survey datasets, Ge and Ho show how STEM students in East Asia are likely to receive better funding when the status of the doctoral programs is the result of government to government agreements as well as direct government funding of applied science and technology research, STEM students also experience better facilities, better research internship opportunities during the doctoral programme, and correspondingly, a wider range of career plans which include academic and industry job prospects.

But how do doctoral students themselves evaluate their own competencies and in what ways do their evaluations shape their career plans? Horta examines how doctoral students evaluate their skill competency and how this relates to their career plans and choices. He finds that those who evaluate themselves higher on research skills are more likely to choose academic jobs while those who see themselves as having stronger management and teaching skills are likely to choose jobs outside of academia.

Within the United States, the academic job market has shrunk with fewer tenured and tenure-track posts and an increased use of part-time faculty. The quality and value of graduate education has come into question in conjunction with high attrition rates in doctoral education. The study by Kim and colleagues drawing on the insights provided by Social Cognitive Career Theory, show how doctoral competency, learning experience, and the organizational culture of graduate schools influence doctoral students' interests in pursuing an academic career.

Turning to China, the study by Shen and his colleagues find that there is a notable differentiation between graduates' employment preferences and the actual outcomes. The proportion of employment in academic institutions is much lower than expected, particularly among female graduates. The significant influencing factors of $\mathrm{PhD}$ graduates' actual employment are gender, university ranking, and personal academic achievements.

As a collection of papers on graduate student training, these articles in the special issue provide a systematic analysis on the student perspectives of doctoral programmes at top research universities. Specifically, the special issue examines the learning process in the doctoral programmes and how different factors contribute to how students assess the skill sets they acquire. Their socio-economic status, disciplinary backgrounds as well as their experience in the doctoral programme in turn shape their career expectations.

As research universities in Asia have increasingly internationalized, the number of international faculty will continue to grow. The second part of this special issue examines the characteristics of selected universities in China, Japan, 
Korea, and Malaysia. Other aspects of internationalization of higher education in the Asian region have been studied, such as international mobility of students, academic programs, and campuses, and inter-regional collaboration in teaching and research activities (Altbach and Balan 2007; Corley and Sabharwal 2007). However, despite rapidly growing numbers of international faculty in Asian universities (Huang 2014, 2015a, b), little is known about them. Therefore, this section analyses and discusses key personal, educational, and professional characteristics of international faculty who have been hired in four Asian colleges and universities in China, Japan, Korea, and Malaysia. The analysis included their roles in these countries, their views of relevant aspects of higher education, and the impact associated with the presence of international faculty in university campuses in Asia. The data collection for these studies included interviews, case studies and national surveys of international faculty, as well as analysis of national policies.

$\mathrm{Wu}$ and Huang mainly use relevant findings from case studies of four leading universities in Shanghai and explore key characteristics of international faculty in China by disciplines, age, and gender. Further, their study also discusses why international faculty came to these universities.

$\mathrm{Li}$ and associates examine the "transnational capital" of "Thousand Youth Talent Scholars" (a national program which is led, financed and implemented by the Chinese government to attract top-level talents or scientists to Chinese universities from all over the world). The study found that scholars under this scheme are highly productive, transferring the knowledge, skills, social networks, and resources obtained overseas to enhance their career development.

Based on main findings from interviews with six Korean faculty in senior manager positions of a research focused university, Shin and Gress explore how international faculty experienced changes in their academic careers after they joined a research focused university and how Korean faculty members perceive these changes.

Huang collected and analyzed data on the main characteristics and roles of international faculty at Japanese universities. His study divides all international faculties into three broad groups: those from Asian societies, those from North America, and European countries, as well as the Pacific region, and others. By making this key division, the study identifies their personal, educational, and professional characteristics, time allocation on teaching, research, social service, and other academic activities, and major work roles they play in their respective affiliations.

Wan and Sirat examine the issues of recruitment, integration, and retention of international academics in three public research universities in Malaysia. First, Malaysia aspires for its higher education to be relevant, externally refereed, and respected globally. Second, international academics, who are non-Malaysian citizens, made up an important part of the talent pool. Third, a typology of international academics in Malaysian universities is proposed to enable a more focused deliberation of the continued recruitment, integration, and retention of international academics.

Collectively, the doctoral student and faculty perspectives explored in this set of papers point to the growing internationalization, productivity, and mobility experienced by East Asian research universities as they continue to deepen their approach to internationalization, and take a leading role in shaping the global academy in the decades to come.

\section{References}

Altbach, P., \& Balan, J. (2007). World class worldwide: Transforming research universities in Asian and Latin America. Baltimore: Johns Hopkins University Press.

Byun, K., Jon, J. E., \& Kim, D. (2013). Quest for building world-class universities in South Korea: Outcomes and consequences. Higher Education, 65, 645-659.

Corley, E. A., \& Sabharwal, M. (2007). Foreign born academic scientists and engineers: Producing more and getting less than their U.S. born peers? Research in Higher Education, 48(8), 909-940.

Faupel-Badger, J. M., Raue, K., Nelson, D. E., \& Tsakraklides, S. (2015). Alumni perspectives on career preparation during a postdoctoral training program: A qualitative study. CBE-Life Sciences Education, 14(1), 1-8.

Gibbs, K. D., McGready, J., \& Griffin, K. (2015). Career development among American biomedical postdocs. CBE-Life Sciences Education, 14(4), 1-12.

Ho, K. C. (2014). International higher education ambitions and regional migration supports. TRaNS: Trans-Regional and-National Studies of Southeast Asia, 2(02), 163-182.

Huang, F. (2014). Chapter 1 The internationalization of the academic profession. In F. Huang, M. Finkelstein, \& M. Rostan (Eds.), The internationalization of the academy: Changes, realities and prospects (The changing academy-The changing academic profession in international comparative perspective (Vol. 10, pp. 1-21). Dordrecht: Springer.

Huang, F. (2015a). Building world class research universities: A case of China. Higher Education, 70(2), 203-215.

Huang, F. (2015b). Chapter 2-International mobility of students, academics, educational programs, and campuses in Asia. In $\mathrm{Ng} \mathrm{C}$. Fox \& R. Nakano M. (Eds.), Reforming learning and teaching in Asia-Pacific Universities (pp. 29-47). Singapore: Springer.

Marginson, S. (2007). Global university rankings: Implications in general and for Australia. Journal of Higher Education Policy and Management, 29(2), 131-142.

Mohrman, K., Ma, W., \& Baker, D. (2008). The research university in transition: The emerging global model. Higher Education Policy, 21(1), 5-27.

Postiglione, G. (2015). Research universities for national rejuvenation and global influence: China's search for a balanced model. Higher Education, 70(2), 235-250.

Postiglione, G. A. (2013). Anchoring globalization in Hong Kong's research universities: Network agents, institutional arrangements, and brain circulation. Studies in Higher Education, 38(3), $345-366$.

Rosenzweig, M. R. (2008). Higher education and international migration in Asia: Brain circulation. In J. Y. Lin \& B. Pleskovic (Eds.), Annual World Bank conference on development economics 
(pp. 59-100) Washington DC: International Bank for Reconstruction and Development/World Bank.

Soofi, A. S. (2016). A comparative study of Chinese and Iranian Science \& Technology, and techno-industrial development policies. Technological Forecasting and Social Change. https://doi. org/10.1016/j.techfore.2016.06.017
Wong, C. Y. (2013). On a path to creative destruction: Science, technology and science-based technological trajectories of Japan and South Korea. Scientometrics, 96(1), 323-336. 